\title{
KEANEKARAGAMAN ANGGOTA FAMILI LAURACEAE DI TAMAN HUTAN KOTA M. SABKI KOTA JAMBI
}

\author{
Rike Puspitasari Tamin ${ }^{1}$, Maria Ulfa ${ }^{1}$ dan Zuhratus Saleh ${ }^{1}$ \\ ${ }^{1}$ Dosen Fakultas Kehutanan Universitas Jambi \\ Kampus Pinang Masak, Mendalo-Indah Jambi 36361 \\ email: rikepuspitasari_unja@yahoo.co.id,ulfaabubakar@gmail.com, \\ zuhratussaleh@ymail.com
}

\begin{abstract}
ABSTRAK
Keluarga Medang-medangan (Famili Lauraceae) merupakan salah satu kelompok tumbuhan yang banyak ditemukan di daerah tropis. Lauraceae juga termasuk kelompok yang paling banyak dimanfaatkan dan bernilai ekonomi tinggi. Pemanfaatan intensif dan nilai ekonomi yang tinggi tidak diimbangi dengan usaha konservasi yang memadai membuat Famili Lauraceae menjadi rentan dalam kepunahan. Permasalahan yang muncul dari keinginan untuk melakukan konservasi bagi Famili Lauraceae adalah sangat minimnya pengetahuan tentang jenis serta nama ilmiah yang benar. Taman Hutan Kota Muhammad Sabki merupakan hutan kota yang diperlukan karena fungsinya antara lain memperbaiki dan menjaga iklim mikro dan nilai estetika, meresapkan air, menciptakan kesimbangan dan keserasian lingkungan fisik kota, dan mendukung pelestarian keanekaragaman hayati di Indonesia. Peneliti tertarik untuk melakukan eksplorasi botani dan identifikasi terhadap keanekaragaman jenis famili Lauraceae yang berada di taman hutan kota Muhammad Sabki. Penelitian dilakukan ada bulan AgustusOktober 2017 di taman Hutan Kota M. Sabki. Kesimpulan yang dapat diambil dari penelitian ini adalah anggota family Lauraceae di Hutan Kota M. Sabki ditemukan berjumlah 12 spesies dengan indeks keanekaragaman Shannon-Wiener 2,36.
\end{abstract}

Kata Kunci: Eksplorasi, Lauraceae, Keanekaragaman, Taman Hutan Kota M. Sabki.

\section{PENDAHULUAN}

Keluarga Medang-medangan (Famili Lauraceae) merupakan salah satu kelompok tumbuhan yang banyak ditemukan di daerah tropis. Famili Lauraceae memiliki sekitar 45 genus dan lebih dari 2000 spesies yang tersebar paling banyak di daerah tropis asia tenggara dan amerika. Lauraceae juga termasuk kelompok yang paling banyak dimanfaatkan dan bernilai ekonomi tinggi (Wen, 1982).

Lauraceae secara umum berbentuk pohon, semak, berbau aromatik, daun tunggal, tersebar, jarang berhadapan, tulang daun pinnatus, tanpa stipula. Bunga axillar, dalam tipe perbungaan panicula, spica, racemosa atau umbella; bunga biasanya bisexual, kadang-kadang unisexual, aktinomorf; perianthium kecil, sepal 6 dalam lingkaran, bersatu membentuk tabung pada dasar; corolla tidak ada; stamen dalam lingkaran masing-masing 3 helai melekat pada tabung kalix, 1 atau lebih lingkaran berupa staminodium; pistilium tunggal dengan carpel, 1 ruang, 1 ovul, placenta margina, ovari superior, stylus 1, stigma 1. Buah drupa atau bacca, sering ada kupula pada basal sebagai derivat dari tabung calyx yang persisten. Biji dengan embrio yang besar, tanpa endosperm (Kostermans, 1957) 
Secara ekonomis, famili Lauraceae memiliki manfaat ekonomi yang dominan sebagai penghasil cinnamon dan camphor (minyak atsiri) oleh genus Cinnamomum, komoditi buah oleh Persea dan kayu bahan bangunan oleh beberapa genus lainnya seperti Beilschmeidia, Endiandra, Ocotea dan Litsea. Beberapa genus lainnya seperti Laurus, Lindera dan Actinodaphne juga berpotensi sebagai tanaman hias. Beberapa jenis obat tradisional juga menggunakan jenis-jenis tumbuhan dari famili Lauraceae dalam bahan pembuatannya dan peracikannya (Heyne, 1987; Hasanah, 2004; Andianto, 2015).

Permasalahan yang muncul dari keinginan untuk melakukan konservasi bagi Famili Lauraceae adalah sangat minimnya pengetahuan tentang jenis serta nama ilmiah yang benar. Informasi tentang nama ilmiah mutlak diperlukan dalam mendata spesies yang masih tertinggal, demikian pula dengan data pendukung ekologis dari setiap spesies yang didata tersebut. Herbarium merupakan institusi yang berwenang dalam memvalidasi nama ilmiah suatu spesies dan menjadi rujukan bagi ahli tumbuhan di dunia untuk melihat dan mengenal spesies tumbuhan.

Herbarium Fakultas Kehutanan Universitas Jambi adalah institusi yang baru dan sedang berkembang sebagi salah satu pusat studi dan pengenalan flora khas hutan tropis terutama dataran rendah Provinsi Jambi. Koleksi tumbuhan yang lengkap dan terstandar menjadi syarat mutlak agar institusi ini menjadi dikenal dan diakui pada tingkat nasional maupun internasional. Koleksi sampel dan nama ilmiah dari Famili Lauraceae yang merupakan salah satu kelompok tumbuhan paling banyak di dataran rendah Jambi merupakan nilai tambah dalam meningkatkan mutu institusi.

Hutan Kota Muhammad Sabki yang terletak di Kelurahan Kenali Asam Bawah Kecamatan Kota Baru dikelola oleh Pemerintah Kota Jambi melalui kantor kehutanan. Pemerintah Kota Jambi mengabadikan nama Walikota Jambi periode 1993-1998, Drs. H. Muhammad Sabki. Pada awalnya, hutan kota hanya memiliki luasan 10 hektar. Namun pada tahun 2003 terjadi perluasan areal menjadi 11 hektar berdasarkan SK Walikota No. 607 Tahun 1995. Dan kemudian, pada tahun 2009 keluar Peraturan Daerah No. 7 Tahun 2009 tentang penetapan nama hutan kota menjadi Taman Hutan Kota Muhammad Sabki (THK. M.Sabki).

Dalam rangka melakukan kegiatan konservasi dan pelestarian tumbuhan hutan tropis secara menyeluruh dengan latar belakang yang dijelaskan sebelumnya, dan dengan beragamnya jenis tanaman yang ada di Taman Hutan Kota Muhammad Sabki, peneliti tertarik untuk melakukan eksplorasi botani dan identifikasi terhadap keberadaan jenis famili medangmedangan (Lauraceae) yang berada di taman hutan kota Muhammad Sabki. Kegiatan ini menjadi penting untuk dilakukan guna konservasi dan pelestarian tumbuhan hutan khas jambi yang berkelanjutan.

\section{METODE PENELITIAN}

Penelitian ini akan dilaksanakan selama tujuh bulan dari Bulan April Mei sampai dengan Bulan Oktober tahun 2017. Penelitian ini akan dilaksanakan di Taman Hutan Kota Muhammad Sabki, Jambi dan Laboratorium Herbarium Fakultas Kehutanan Universitas Jambi. Alat dan bahan yang diperlukan didalam penelitian ini terbagi menjadi 3 bagian, yaitu: 
1. Alat dan bahan pengumpulan sampel; adapun alat yang digunakan yaitu gunting stek, plastik, kertas label, benang wol, pensil, kertas koran, galah, dan Global Positioning System (GPS). Adapun bahan yang digunakan dalam pengumpulan sampel yaitu material yang memiliki ciri khas yang lain seperti bunga, buah, dan lainnya serta alkohol $70 \%$.

2. Alat dan bahan pengepresan dan pengeringan; adapun alat yang digunakan yaitu kertas koran, seng bergelombang, karton begelombang, papan sasak, pengikat sasak, serta oven. Sedangkan bahan yang diperlukan dalam kegiatan pengepresan dan pengeringan diperlukan sampel yang telah diberikan alkohol 70\%.

3. Alat dan bahan pengeplakan dan mounting; adapun alat yang digunakan yaitu kertas bebas asam, selotip, kertas label, kertas jagung kuning, jarum, benang sol, cutter, gunting, pensil, penghapus dan amplop. Sedangkan bahan yang diperlukan dalam kegiatan pengoleksian adalah sampel yang telah dikeringkan.

Metode pengambilan langsung dilakukan pada setiap perjumpaan dengan jenis yang diduga family Lauraceae. Hal ini untuk menjamin pengambilan specimen yang menyeluruh dari setiap jenis dari family lauraceae yang ada di THK M. Sabki. Pengambilan semua sampel/specimen tumbuhan di lapangan dilakukan dengan standar pembuatan herbarium.

\section{HASIL DAN PEMBAHASAN}

Eksplorasi Famili Lauraceae di Hutan Kota M. Sabki telah dilakukan pada bulan AgustusOktober 2017. Dari eksplorasi tersebut didapatkan hasil sebanyak 13 spesies dari family lauraceae. Deskripsi dari 13 spesies hasil eksplorasi adalah sebagai berikut (Kostermans 1957; Wen, 1982; Heyne 1987):

1. Alseodaphne bancana Miq.

Alseodaphne bancana Miq. merupakan jenis lauraceae dengan habitus pohon yang dapat mencapai tinggi $40 \mathrm{~m}$ dan diameter mencapai $66 \mathrm{~cm}$. Jenis ini biasa ditemukan pada pada tipe hutan dipterocarpaceae, rawa, kerangas dan hutan pegunungan bawah. Jenis ini tumbuh pada daerah punggung bukit, lembah, dekat sungai dan rawa dengan ketinggian sampai 1100 mdpl.

Alseodaphne bancana Miq. diketahui bermanfaat kayunya dan dikenal dengan nama Medang. Kayunya dapat digunakan untuk konstruksi dan juga pembuatan kapal. Kayunya termasuk kayu yang mudah untuk diolah dan cocok untuk plywood, furniture dan meubel lainnya.

2. Alseodaphne lancilimba

Alseodaphne lancilimba merupakan jenis lauraceae dengan habitus pohon dan bentuk hidupnya teresterial. Jenis ini dapat tumbuh hingga $40 \mathrm{~m}$ dan diameter mencapai 100 m. Jenis ini sering ditemukan di dataran rendah sampai $300 \mathrm{mdpl}$ dengan habitat hutan sekunder dan hutan karet. Jenis ini juga dikenal hanya dengan nama Medang dan dimanfaatkan kayunya terutama untuk furniture.

3. Alseodaphne obovata Kosterm.

Alseodaphne obovata merupakan jenis dengan lauraceae dengan habitus pohon dengan cabang yang menyebar dan kulit batang coklat kehitaman. Jenis ini juga dikenal dengan nama Medang dan menyebar di hutan primer dan sekunder terutama 
pada daerah dataran rendah sampai pegunungan bawah. Jenis ini juga banyak dimanfaatkan sebagai kayu pertukangan karena kualitas kayu yang cukup baik.

4. Cinnamomum burmannii (Nees \& T. Nees) Blume

Cinnamomum burmannii merupakan anggota Lauraceae yang telah dikenal luas dan dimanfaatkan di seluruh dunia. Cinnamomum burmannii dikenal dengan nama dagang Batavia Cinnamon serta nama local kayu manis dan kulit manis. Jenis ini sering berupa pohon kecil dengan tinggi mencapai $15 \mathrm{~m}$ dan diameter $30 \mathrm{~cm}$. Jenis ini dapat tumbuh di ketinggian sampai $2000 \mathrm{~m}$ dan tumbuh maksimal di rentang 300$1500 \mathrm{~m}$ dengan suhu optimal $20^{\circ}-28^{\circ} \mathrm{C}$.

Cinnamomum burmannii dapat dimanfaat mulai dari batang, daun dan terutama kulitnya. Batangnya dapat dimanfaatkan sebagi kayu pertukangan sementara kulitnya sudah dikenal di seluruh dunia sebagai salah satu bumbu utama. Penelitian lebih lanjut mengungkapkan bahwa kulit Cinnamomum burmannii berpotensi dan telah diuji dalam berbagai pengobatan. Cinnamomum burmannii termasuk jenis yang telah dibudidayakan sehingga dapat tumbuh dan tersedia untuk memenuhi kebutuhan industry dunia.

5. Cinnamomum porrectum (Roxb.) Kosterm.

Cinnamomum porrectum dikenal dengan nama Safrol laurel (English), Medang Lesah, Ki Sereh (Sunda), Rawali (Kalimantan), Medang Kemangi ( Malaysia) dan Keplah Wangi ( Sarawak). Jenis ini dapat ditemukan mulai dari Burma, semenanjung Malaya, cina selatan sampai ke Sumatera, jawa dan Kalimantan. Cinnamomum porrectum merupakan jenis pohon dengan ketinggian mencapai $45 \mathrm{~m}$ dan diameter $105 \mathrm{~cm}$. Batangnya berbentuk bulat silinder dan biasanya tegak lurus semenara kulit batangnya sering terlihat pecah dan berwarna merah kecoklatan. Cinnamomum porrectum tersebar secara luas dan umumnya ditemukan pada hutan dataran rendah sampai hutan pegunungan.

6. Dehaasia membranacea Kosterm.

Dehaasia membranacea sering ditemukan di dataran rendah sampai $300 \mathrm{mdpl}$ dengan habitat hutan sekunder dan hutan karet. Jenis ini juga dikenal hanya dengan nama Medang dan dimanfaatkan kayunya terutama untuk furniture.

7. Endiandra immerse Arifiani

Jenis ini juga dikenal hanya dengan nama Medang dan dimanfaatkan kayunya terutama untuk furniture

8. Eusideroxylon zwagerii Teijsm \& Binn.

Eusideroxylon zwagerii merupakan slow growing species yang dapat tumbuh mencapai ketinggian $50 \mathrm{~m}$ dan diameter $220 \mathrm{~cm}$. Jenis termasuk jenis lauraceae yang paling banyak dimanfaatkan kayunya karena memiliki kualitas sangat baik dan dikenal dengan nama Ironwood (English), Kayu Besi, Ulin (Kalimantan) dan Bulian (Jambi/Sumatera).

Eusideroxylon zwagerii dapat ditemukan pada hutan primer dataran rendah sampai hutan sekunder tua pada daerah hutan dataran rendah sampai $400 \mathrm{mdpl}$ dan dapat tumbuh pada daerah datar maupun kemiringan. Pada tahap budidaya, jenis ini mampu tumbuh hingga $625 \mathrm{mdpl}$ dengan kondisi suhu optimal $20^{\circ}-30^{\circ} \mathrm{C}$ dan curah 
hujan 2500-4000 mm/tahun. Pada tahap pertumbuhan semai, jenis ini memerlukan naungan untuk pertumbuhannya sementara ketika sudah dewasa jenis ini membutuhkan banyak cahaya matahari.

Eusideroxylon zwagerii banyak dimanfaatkan kayunya dalam kegiatan yang membutuhkan kayu yang berat dan tahan lama seperti kapal, bendungan, pelabuhan dan rel kereta api. Jenis ini juga dimanfaatkan sebagai bahan rumah adat suku dayak di Kalimantan sementara di Cina dimanfaatkan sebagai keranda mayat. Karena kualitasnya kayunya yang tinggi, jenis ini tidak cocok dipakai sebagai plywood atau pemanfaatan kayu partikel lainnya.

9. Litsea elliptica Blume

Litsea elliptica merupakan anggota Lauraceae dengan habitus pohon yang dapat tumbuh mencapai $44 \mathrm{~m}$ dan diameter $78 \mathrm{~cm}$. Jenis ini sering dimanfaatkan secara local oleh masyarakat dan dikenal kayunya dengan nama Medang. Jenis ini dapat ditemukan pada daerah hutan dataran rendah dipterocarpaceae sampai hutan pegunungan bawah dengan ketinggian samapi 1200 mdpl. Jenis ini dapat tumbuh di daerah berbukit dan dekat dengan air serta dapat tumbuh di daerah tanah berpasir.

Litsea elliptica merupakan jenis yang cukup aromatic yang tercium pada daun, bunga, batang dan kulit kayunya. Daunnya dimanfaatkan sebagai lalapan di Thailand sebagai pelengkap masakan tradisional karena menimbulkan sensasi pedas. Kayunya dipakai sebagai bahan bangunan dan juga dimanfaatkan sebagai bahan mortar.

10. Litsea oppositifolia Gibbs.

Litsea oppositifolia merupakan salah satu jenis lauraceae dengan habitus pohon. Buahnya berbentuk drupe dan hidupnya pada teresterial. Jenis ini biasa ditemukan dalam hutan primer dan sekunder. Jenis ini juga dikenal hanya dengan nama Medang dan dimanfaatkan kayunya terutama untuk furniture

11. Litsea robusta Blume

Litsea robusta merupakan jenis dari lauraceae dengan habitus pohon yang mampu mencapai ukuran tinggi $25 \mathrm{~m}$ dan diameter $50 \mathrm{~cm}$. Tumbuhan ini bisa ditemukan pada hutan dataran rendah, hutan dipterocapaceae hingga hutan pegunungan dengan ketinggian $1700 \mathrm{mdpl}$. Jenis ini juga dikenal hanya dengan nama Medang dan dimanfaatkan kayunya terutama untuk furniture.

12. Litsea umbellata (Lour..) Merr.

Litsea umbellata merupakan anggota lauraceae yang hidup di hutan kota M. Sabki. Jenis ini sering dimanfaatkan secara local oleh masyarakat dan dikenal kayunya dengan nama Medang. Jenis ini dapat ditemukan pada daerah hutan dataran rendah dipterocarpaceae sampai hutan pegunungan bawah dengan ketinggian sampai 1200 mdpl.

Dari penjelasan berbagai spesies family lauraceae tersebut dapat dilihat bahwa secara umum hampir semua jenis lauraceae dikenal baik di masyarakat di berbagai penjuru dunia. Eusideroxylon zwageri atau lebih dikenal dengan bulian/ulin sudah terkenal sejak lama kualitas kayunya dan berakibat mengalami eksploitasi berlebih tanpa usaha budidaya sehingga jenis ini semakin berkurang secara alami di alam. Red List IUCN bahkan 
memasukkan jenis ini dalam kategori Vulnerable, yaitu suatu kategori kelompok mulai genting dan menuju kepunahan. Akhir-akhir ini Fakultas Kehutanan UNJA giat dalam membudidayakan jenis ini dan kembali mempromosikannya sebagai jenis khas dari jambi.

Cinnamomum burmanni atau lebih dikenal dengan kayu manis juga sudah memiliki pasar sendiri sejak dahulu. Jenis ini lebih beruntung karena sudah dibudidayakan secara intensif pada berbagai kawasan sehingga walaupun terjadi eksploitasi namun populasi di alam masih tetap stabil.

Selain jenis Eusideroxylon zwagerii dan Cinnamomum burmannii, semua jenis yang didapatkan pada penelitian ini dikenal hanya dengan nama Medang. Semua jenis ini dikenal karena produksi kayunya. Karena inilah family lauraceae juga dikenal sebagai family/kelompok medang-medangan. Kurangnya penjelasan dari spesies-spesies ini karena kurangnya data dan informasi terkait seperti perbanyakan dan budidaya. Spesies-spesies ini masih dimanfaatkan secara langsung dari alam sehingga dikhawatirkan juga akan menurunkan populasinya di alam.

Penghitungan indeks Shannon-Wiener dilakukan setelah mendapatkan jumlah individu masing-masing spesies anggota Lauraceae di THK. M.Sabki. Tabel 1 berikut memuat perhitungan indeks keanekaragaman Shannon-Wiener family lauraceae di THK. M.Sabki.

Tabel 1. Indeks Keanekaragaman Shannon-Wiener Family Lauraceae di THK M.Sabki

\begin{tabular}{clcc}
\hline No. & Spesies & Jumlah Individu & H' \\
\hline 1 & Alseodaphne bancana & 3 & 0,09 \\
2 & Alseodaphne lancilimba & 12 & 0,23 \\
3 & Alseodaphne obovata & 19 & 0,29 \\
4 & Cinnamomum burmannii & 18 & 0,28 \\
5 & Cinnamomum porrectum & 12 & 0,23 \\
6 & Dehaasia membranacea & 12 & 0,23 \\
7 & Endiandra immerse & 9 & 0,19 \\
8 & Eusyderoxylon zwageri & 11 & 0,22 \\
9 & Litsea elliptica & 9 & 0,19 \\
10 & Litsea oppositifolia & 10 & 0,20 \\
11 & Litsea robusta & 3 & 0,09 \\
12 & Litsea umbellata & 4 & 0,11 \\
\hline & & $\mathbf{1 2 2}$ & $\mathbf{2 , 3 6}$
\end{tabular}

Perhitungan indeks keanekaragaman menunjukkan nilai $H^{\prime}$ sebesar 2,36. Nilai ini berarti bahwa keanekaragaman family lauraceae tergolong sedang dengan standar nilai H' berada antara 1-3. Keanekaragaman dikatakan rendah jika nilai $\mathrm{H}^{\prime}$ kurang dari 1, dikatakan sedang jika berada antara 1-3, dan dikatakan tinggi jika nilai H' diatas 3.

\section{KESIMPULAN}

Kesimpulan yang dapat diambil dari penelitian ini adalah terdapat anggota famili Lauraceae di Hutan Kota M. Sabki sejumlah 12 spesies dengan indeks keanekaragaman tergolong sedang dimana H' Shannon-Wiener 2,36. 


\section{UCAPAN TERIMA KASIH}

DIPA PNBP LPPM Kelompok Dosen Pemula Universitas Jambi Tahun Anggaran 2017 dengan No. SP DIPA-042.01.2.400950/2017 Surat Perjanjian Kontrak Nomor: 197/UN21.17/PP/2017. Terima kasih juga kepada pihak Taman Hutan Kota Muhammad Sabki atas kerjasamanya serta mahasiswa yang membantu sepanjang penelitian ini berlangsung.

\section{DAFTAR PUSTAKA}

Andianto, I. Wahyudi, T.K. Waluyo, R. Dungane, A. Hadiyane and M.F.Hernandi. 2015. Wood anatomical from Indonesian genus Cinnamomum (Lauraceae) and their identification keys. Asian J. Plant Sci 14 (1): 11-19, 2015

Hasanah, M., Y. Nuryani, A. Djisbar, E. Mulyono, E. Wikardi and A. Asman, 2004. Indonesian Cassia (Indonesian Cinnamon). Medicinal and Aromatic PlantsIndustrial Profiles. CRC Press, New York, Washington, DC.

Heyne, K. 1987. Tumbuhan Berguna Indonesia. Jilid I dan II. Terj.Badan Libang Kehutanan. Cetakan I. Koperasi karyawan Departemen Kehutanan Jakarta Pusat

Kostermans,A.J.G.H. 1957. Lauraceae. Reinwardtia Vol 4(2) : 193-256.

Li Hsi-wen et al. 1982. Lauraceae. In: Li Hsi-wen, ed., Fl. Reipub 1. Popularis Sin. 31: 1-46 